\title{
Translation and validation of the Short HIV Stigma scale in Brazilian Portuguese
}

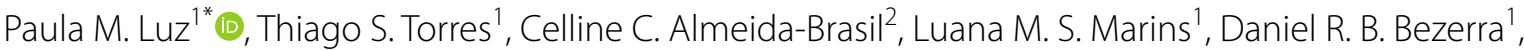 \\ Valdilea G. Veloso ${ }^{1}$, Beatriz Grinsztejn' ${ }^{1}$, Daphna Harel ${ }^{3,4}$ and Brett D. Thombs ${ }^{5,6}$
}

\begin{abstract}
Background: HIV-related stigma, or the degree to which people living with HIV endorse negative stereotypes associated with HIV, is associated with poor continuum of care outcomes. We translated the 12-item Short HIV Stigma scale and evaluated its psychometric properties in a Brazilian context with regard to construct validity and reliability.

Methods: The first step included translation, back-translation, evaluation, peer review, and pre-testing of the Short HIV Sigma scale developed by Reinius et al. (Health Qual Life Outcomes 15(1):115, 2017).The second step involved piloting the scale in three convenience samples of adults recruited online through advertisements on different platforms: Grindr (October/2019) and Hornet (February-March/2020), geospatial network apps for sexual encounters for gay, bisexuals and other men who have sex with men, and social media apps (Facebook and WhatsApp, October/2019). The psychometric evaluation included confirmatory factor analysis, differential item functioning using the Multiple-Indicator Multiple-Cause model, and correlations between subscale scores and antiretroviral treatment use and adherence. Reliability was assessed using Cronbach's alpha, and ordinal alpha and omega from the polychoric correlation matrix.
\end{abstract}

Results: In total, 114, 164, and 1824 participants completed the measure items through Grindr, social media, and Hornet, respectively. We confirmed a 4-factor structure with factors for personalized stigma (3 items), disclosure concerns (3 items), concerns with public attitudes (3 items), and negative self-image (3 items). Small differential item functioning with respect to sample was found for one item ("I feel guilty because I have HIV"), which did not substantively influence estimates of latent factor scores. Grindr and Hornet's participants scored significantly higher than social media participants on all factors except personalized stigma. Higher subscale scores correlated with antiretroviral treatment use among participants from Hornet and with lower treatment adherence in participants from Grindr and Hornet. Reliability as measured by Cronbach's alpha, ordinal alpha and omega were 0.83, 0.88 and 0.93 for the entire scale.

Discussion: The Brazilian Portuguese version of the Short HIV Stigma scale had satisfactory psychometric properties with present results suggesting that scores from different samples may be compared without concern that measurement differences substantively influence results though further studies with greater representation of women and heterosexual men are warranted.

Keywords: HIV-related stigma, HIV/AIDS, Validation, Psychometric properties, Portuguese, Brazil

*Correspondence: paula.luz@ini.fiocruz.br; luzpaulamendes@gmail.com 1 Instituto Nacional de Infectologia Evandro Chagas, Fundação Oswaldo Cruz, Av. Brasil 4365, Manguinhos, Rio de Janeiro 21040-900, Brazil Full list of author information is available at the end of the article

\section{Background}

As the HIV epidemic continues to spread in Brazil, the cumulative number of individuals with HIV/AIDS is reaching 1 million in 2020. Brazil's HIV epidemic has, since its onset, been concentrated in key populations original author(s) and the source, provide a link to the Creative Commons licence, and indicate if changes were made. The images or other third party material in this article are included in the article's Creative Commons licence, unless indicated otherwise in a credit line to the material. If material is not included in the article's Creative Commons licence and your intended use is not permitted by statutory regulation or exceeds the permitted use, you will need to obtain permission directly from the copyright holder. To view a copy of this licence, visit http://creativecommons.org/licenses/by/4.0/. The Creative Commons Public Domain Dedication waiver (http://creativeco mmons.org/publicdomain/zero/1.0/) applies to the data made available in this article, unless otherwise stated in a credit line to the data. 
such as sex workers; people who use drugs; gay, bisexual and other men who have sex with men (GBM); and transgender people [1]. Indeed, though the epidemic is classified as stable at the national level, with prevalence of $0.4 \%$ in the general population [2], HIV prevalence is significantly higher in these key populations [2]. Moreover, prevalence varies geographically with a marked spatial-temporal expansion of the HIV epidemic from the major cities of the Southeast to the other regions [3].

Over the past three decades, Brazil's response to the HIV epidemic has been strong, often leading the way when compared to other low- and middle-income countries. There are important inequities in the system, however. Black race, lower education, residing in a less developed region (most notably the North and Northeast), and high levels of social vulnerability are all independently associated with a higher likelihood of presenting to care with more advanced disease, not using antiretroviral therapy, and not achieving viral suppression [4]. An important driver of these findings may be the different forms of stigma and discrimination that are prevalent in the Brazilian society [5].

Among GBM, different forms of stigma, including internalized, perceived, experienced, and layered stigmas have been shown to significantly impact health outcomes related to HIV [6]. In Brazil, a study conducted in 20082009 in a national sample of GBM from 10 cities reported that $16 \%$ of participants experienced lifetime sexual violence and that the strongest predictor of sexual violence was homophobic discrimination [7]. In another analysis, concerns about confidentiality and fear of stigma and discrimination impacted HIV testing frequency [8]. A study conducted in Bahia in 2010-2011 further suggests how stigma of same-sex behavior might contribute to people living with HIV presenting to care with advanced disease [9]. Beyond sexual minority stigma, a study conducted in Belo Horizonte observed that black persons had more than $50 \%$ higher odds of experiencing discrimination than white persons in health care settings, even after controlling for income, education, social status, and health problems [10]. A call has been made for the study of the convergence of multiple stigmatized identities [11] which, for people living with HIV, will need to include the measuring and impact of HIV-related stigma.

HIV-related stigma may be broadly defined as the degree to which people living with HIV endorse negative stereotypes associated with HIV [12]. Over the past two decades, studies have shown how HIV-related stigma may affect health outcomes [13, 14]. A 2016 meta-analysis of 64 studies conducted mostly in developed countries (none in Brazil) showed that HIV-related stigma was associated with higher levels of depression and lower levels of social support, antiretroviral adherence, and access to and usage of health and social services [13]. A 2017 meta-analysis of studies from low- and middle-income countries (only one study from Brazil which evaluated HIV-stigma using a single question), suggested that HIVrelated stigma doubled the odds of presenting to care with advanced disease [14]. In another study among older GBM, authors reported that, among multiple health outcomes explored, HIV-related stigma correlated with the greatest number of factors, including depression, loneliness, and substance use [15].

In Brazil, to date, few studies addressing HIV-related stigma and its impact on health and well-being have been published. In a qualitative content analysis, authors reported that people living with HIV abstain from treatment due to fear of being identified as HIV-infected in the health care setting and facing subsequent discrimination [16]. In a quantitative analysis of 900 individuals with HIV, the authors found a negative correlation between HIV-related stigma and reported physical health [17], while in a study conducted only among women, HIV-related stigma was associated with non-disclosure of HIV status to sexual partners [18]. Finally, a study conducted among 918 women in São Paulo found no association between women's report of stigma in the context of intimate relationships and sexual inactivity [19]. It is important to note that all these studies used different instruments to measure HIV-related stigma and none described the translation and/or validation process of the instruments used.

In March 2019 Brazil joined the UNAIDS and the Global Network of People Living with HIV global assessment of HIV-related stigma (launched in 2008), and applied the stigma index version 2.0 (an 80-item instrument) in a snowball sample of 2000 individuals. Results showed how $82 \%$ of participants find it difficult to disclose their HIV-infection to others with $76 \%$ affirming that they deliberately hide their status [20].

To study HIV-related stigma, a valid and reliable instrument is needed to measure its multiple dimensions [21]. Multiple instruments are available for measuring HIV-related stigma, including full and shortened versions [22-27]. One such instrument is the Berger et al. 40-item HIV Stigma Scale, developed in the United States based on literature and two rounds of content review and psychometric analysis [28]. It measures three different stigma mechanisms as represented in the four dimensions: enacted stigma with the personalized stigma dimension, anticipated stigma with public attitudes and disclosure concerns dimensions, and internalized stigma with negative self-image dimension. The items are statements that a person living with HIV can agree or disagree with using a 4-point Likert-type response. Scoring is based on the summing of the scores for the items 
belonging to each subscale, or all 40-items for an overall stigma score. The Berger et al. HIV Stigma Scale had its psychometric properties evaluated in the Swedish context with regards to construct validity and reliability showing satisfactory results [29] (it has also been translated into other languages [29-32]). Aiming for a significantly shorter instrument, the Berger et al. instrument was later shortened to a 12-items Short HIV Stigma scale in the Swedish context [12]. The shorter instrument is similarly composed of statements with a 4-points Likerttype response and scoring is calculated by summing the 3 items belonging to each of the four subscales meaning that although much shorter in length, it still captures the multiple dimensions of stigma.

In the present study, we performed a translation of the Short HIV Stigma scale to Brazilian Portuguese. In addition, we evaluated its reliability (internal consistency) and construct validity in three convenience samples, each recruited online using different platforms. Furthermore, we tested for differential item functioning (DIF) to determine if any items of the scale had different measurement properties among the groups included in our sample. Items with DIF may be considered to be assessing the target construct plus some additional characteristics that differ among assessed groups. HIV affects distinct population groups that may experience HIV-related stigma differently. The presence of substantive DIF could threaten the validity of group comparisons.

\section{Methods}

\section{Step 1: Translation}

Following established guidelines [33], translation of the items of the Short HIV Stigma scale into Brazilian Portuguese was performed by three independent translators (two researchers and a linguistics professor fluent in both languages), after which a meeting was held to discuss and reach a consensus translated version of the scale.Then, three additional independent reviewers (two language teachers and one professional translator) translated the Portuguese version back to English, after which another meeting was held with the six members of the translation team and a mediator who was also a member of the research team to compare the original items with the back-translated items and identify where items or words seemed to differ. In this final meeting, the team reached an agreed-on version based on the comments, the original items, and the translated items. Next, three experts evaluated the translated items vis-à-vis the original subscales to judge if, in their opinion, they captured the concepts as defined. Finally, a qualitative pretesting of the resulting items was conducted with a small convenience sample to ensure item comprehensibility before moving into the second step of this study. For this, an electronic version of the scale was provided online to a sample of the target group population. Participants were requested to judge the clarity of each item on a scale from 0 to 10; if an item was scored as 7 or lower, an additional open text field was provided and the participant was asked to state what was unclear and to provide suggestions to improve clarity. A group meeting of the research team was held to discuss the suggestions made and items were adjusted as needed to improve understanding.

\section{Step 2: Psychometric evaluation Study design}

This is a methodological study with a cross-sectional design that accessed the reliability and construct validity of the translated Short HIV Stigma scale in convenience samples recruited online in Brazil.

\section{Study population}

Three convenience samples of adult Brazilians were recruited to complete a web-based survey through advertisements on different platforms. During the month of October 2019, the Grindr platform, a geospatial network app for sexual encounters for GBM, was used to recruit GBM whereas social media apps (Facebook and WhatsApp) were used to recruit women and men. During the months of February and March 2020, the Hornet platform, another geospatial network app for sexual encounters for GBM, was used to recruit a second sample of GBM.

For the web-based survey launched in October 2019, given its significant length, random allocation of eligible participants to different instruments was performed to decrease participant burden such that each participant only responded to one instrument. The web-based survey launched in February and March 2020 on Hornet, instead, was reduced in length and did not use random allocation, with participants responding to all survey items applicable to them.

Participant eligibility included age $\geq 18$ years, residency in Brazil, and self-report of HIV-infection. Exclusion criteria was an incorrect response to any of the attention questions which were included throughout the survey instrument at approximately every 15 items, and having responded to the survey previously (Fig. 1: Participant flow chart). This study was approved by INI Evandro Chagas-FIOCRUZ institutional review board (\#CAAE 01777918.0.0000.5262) in accordance with all applicable regulations, and participants provided informed consent prior to being directed to survey items. 


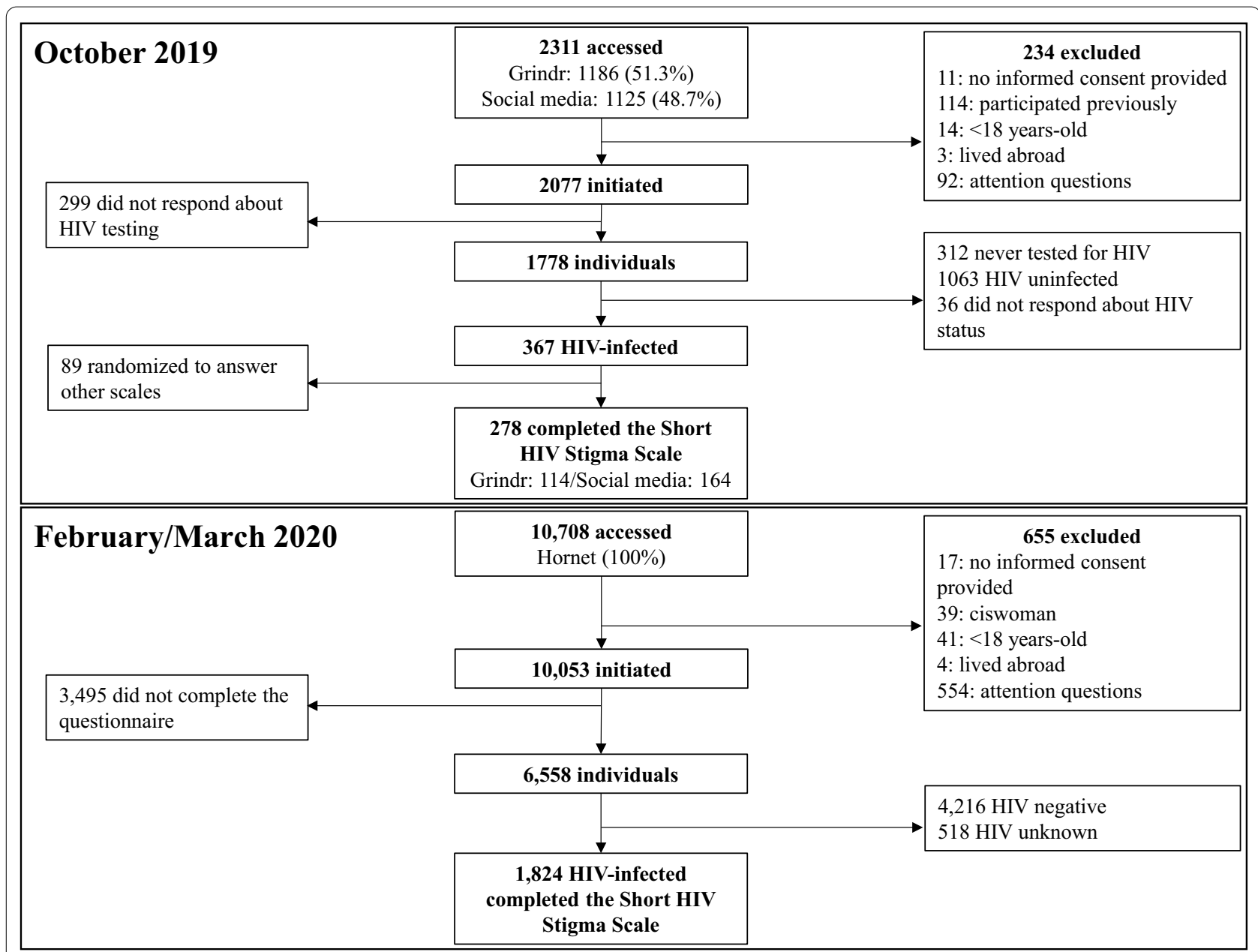

Fig. 1 Study population flow-chart for the two web-based surveys launched in October 2019 and February/March of 2020

\section{Study instrument and measurements}

Relevant to the present study, the survey instrument was divided into four sections as follows. Section 1 included items on socio-demographic information (age, race/ ethnicity, gender, sexual orientation, education, income, state of residence), and Sect. 2 included items referring to prior HIV testing and HIV test results. If HIV-infected, participants answered Sect. 3 which included the items of the translated scale. As in the original scale [12], response options for the translated scale were on a 4-point Likert ranging from strongly disagree (discordo totalmente, 1) to strongly agree (concordo totalmente, 4), and scale scoring was calculated by summing the items of each subscale (subscale range: $3-12$ ).

Section 4 included items on use of antiretroviral treatment (Are you currently using antiretroviral therapy? Yes/No), and if in use, treatment adherence. Treatment adherence was measured using the WebAdQ instrument, a 3-items web-based questionnaire developed from interview and focus groups with people living with HIV in Brazil and subsequently validated in a sample of 74 individuals using antiretroviral treatment for more than 60 days [34]. The items constitute questions (i.e. In the prior 7 days, did you forget to take any of your prescribed pills?) that should be answered as Yes, No, or I don't remember. Scoring is based on the sum of "Yes" responses with adherence defined as a "No" response to all three items. The WebAd-Q instrument was shown to correlate with other measures of adherence (pill count, electronic monitoring and self-report) and with subsequent viral load measurements [34]. Additionally, we also assessed adherence with the question "Please mark below the value that corresponds to how much of your antiretroviral medication you took in the past 30 days?" which was answered on slider using a visual analog scale and adherence was defined using the usual cut-off of $95 \%$ or more [35]. 


\section{Statistical analysis}

Socio-demographic characteristics were described with absolute counts and percentages.

\section{Confirmatory factor analysis}

We first tested the original factor structure of the Short HIV Stigma scale in the three samples separately using confirmatory factor analysis (CFA). Item responses were ordinal Likert data, so the weighted least squares estimator with a diagonal weight matrix, robust standard errors, and a mean- and variance-adjusted chi-square statistic was used with delta parameterization [36]. Modification indices were inspected to identify pairs of items within scales for which model fit would improve if error estimates were freed to covary [37]. To assess model fit, chisquare test, Tucker-Lewis Index (TLI) [38], Comparative Fit Index (CFI) [39], Root Mean Square Error of Approximation (RMSEA) [40], and Standardized Root Mean Square Residual (SRMR) [41] were used. Since chi-square test is highly sensitive to sample size, it can lead to the rejection of well-fitting models [42]. Therefore, the TLI, CFI and RMSEA fit indices were emphasized. Good fitting models were indicated by a TLI and CFI $\geq 0.95$ and RMSEA $\leq 0.06$ [43].

Once the factor structure was established for each sample separately, a CFA model was fit that included participants from two distinct sample populations. As previously described, GBM carry the greatest HIV burden in Brazil with a pattern of increasing incidence in the past decade. Moreover, HIV-infected GBM, as sexual minorities, suffer from other forms of stigma suggesting that they may experience HIV-related stigma differently. Thus, to reach our objective of assessing for the presence of substantive DIF which could threaten the validity of group comparisons, for the analyses that follow, both samples of GBM (Grindr and Hornet) were compared to social media participants separately.

\section{Differential item functioning}

To determine whether Short HIV Stigma Scale items exhibited DIF for Grindr versus social media participants and for Hornet versus social media participants, we followed a pre-established protocol using a multiple indicator multiple cause (MIMIC) model [44-46]. These are models where the relationship between factors and a set of covariates are studied to understand measurement invariance and population heterogeneity. The base MIMIC model consists of the CFA factor model with an added direct effect of group on the latent factors. This serves to control for group differences on the latent factor. Then, each item is separately regressed on group to assess potential DIF, defined as a statistically significant $(p<0.05)$ link of group with the item, controlling for differences in the overall level of the latent factor. Once all items with significant DIF were identified, the magnitude of DIF items collectively was evaluated by comparing the difference on the latent factor between groups in the baseline model and after controlling for DIF.

\section{Reliability}

We estimated each subscale's internal consistency using Cronbach's alpha and assumed it acceptable if $>0.7$ [47]. Additionally, we also estimated two ordinal reliability coefficients, ordinal alpha and omega, from the polychoric correlation matrix [48].

\section{Construct validity}

We used hypothesis testing (Wilcoxon Signed Rank Test for Grindr and social media samples and Student's $t$-test for Hornet sample) to evaluate if subscale scores of the Short HIV Stigma scale differed by use of antiretroviral treatment or treatment adherence for each group separately. We hypothesized that higher scores on the Short HIV Stigma subscales would be associated with a decreased use of antiretroviral treatment and decreased adherence.

CFA and MIMIC analyses were carried out in Mplus version 8.4 , all other analyses were performed in $\mathrm{R}$ version 4.0.2 [49].

\section{Results}

Step 1: Translation

The qualitative pretesting of the final translated version was done with a small convenience sample of the target group population $(\mathrm{N}=11)$, most were aged $25-35$ years (45\%), had finished basic education (45\%), and lived in the city of Rio de Janeiro (73\%). On a scale of 0 to 10 , all items were judged as clear by most participants with a lowest mean clarity score of 8.3 for item 3 ("Some people avoid touching me") and a highest of 10 for item 6 ("I am very careful who I tell"). Two items, 5 and 11, were slightly modified as a function of the suggestions made by participants. The final version of the translated scale is given in Table 1.

\section{Step 2: Psychometric evaluation Sample characteristics}

Socio-demographic characteristics for the three study samples are displayed in Table 2.

Grindr platform In total, 114 cisgender men completed the translated version of the Short HIV Stigma scale. Median age was 38 years (interquartile range $31-46)$, most were white $(63,57 \%), 31$ (27\%) reported high-income, and 83 (73\%) reported college education or higher (more than 12 years of education). Sexual 
Table 1 The 12 final items of the translated short HIV stigma scale

\begin{tabular}{|c|c|c|}
\hline Item\# & Original item & Final Brazilian Portuguese translation \\
\hline & Personalized stigma & \\
\hline 01 & People I care about stopped calling after learning I have HIV & $\begin{array}{l}\text { Pessoas que eu gosto pararam de falar comigo quando souberam que eu } \\
\text { tenho HIV }\end{array}$ \\
\hline 02 & I have lost friends by telling them I have HIV & Já perdi amigos depois de contar que tenho HIV \\
\hline \multirow[t]{2}{*}{03} & Some people avoid touching me once they know I have HIV & Algumas pessoas evitam me tocar depois que descobrem que tenho HIV \\
\hline & Disclosure concerns & \\
\hline 04 & I work hard to keep my HIV a secret & Me esforço para manter em segredo que tenho HIV \\
\hline 05 & Telling someone I have HIV is risky & Tenho receio de contar para alguém que tenho HIV \\
\hline \multirow[t]{2}{*}{06} & I am very careful who I tell that I have HIV & Tomo muito cuidado com quem falo que tenho HIV \\
\hline & Concerns about public attitudes & \\
\hline 07 & Most people believe a person who has HIV is dirty & A maioria das pessoas acredita que quem tem HIV é sujo \\
\hline 08 & People with HIV are treated like outcasts & Pessoas com HIV são marginalizadas \\
\hline \multirow[t]{2}{*}{09} & Most people are uncomfortable around someone with HIV & $\begin{array}{l}\text { A maioria das pessoas se sente desconfortável na presença de alguém com } \\
\text { HIV }\end{array}$ \\
\hline & Negative self-image & \\
\hline 10 & I feel guilty because I have HIV & Me sinto culpado por ter HIV \\
\hline 11 & People's attitudes about HIV make me feel worse about myself & As atitudes das pessoas em relação ao HIV fazem com que me sinta mal \\
\hline 12 & I feel I'm not as good a person as others because I have HIV & Sinto que não sou uma pessoa tão boa quanto as outras por ter HIV \\
\hline
\end{tabular}

orientation was reported as gay/homosexual by 104 (91\%) and bisexual by 10 (9\%). Subscale scores were 5.9 (SD 2.9) for personalized stigma, 11.1 (SD 1.5) for disclosure concerns, 9.8 (SD 1.9) for concerns about public attitudes, and 7.8 (SD 2.6) for negative self-image.

Social media platforms In total, 164 participants completed the translated version of the Short HIV Stigma scale. Median age was 43 years (interquartile range 33-54), 75 (46\%) were white, 93 (57\%) reported low income, and 64 (39\%) reported college education or higher. The majority were cisgender men $(87,54 \%)$ and $12(7 \%)$ were transgender/non-binary. Subscale scores were 5.9 (SD 2.8) for personalized stigma, 8.9 (SD 3.2) for disclosure concerns, 8.7 (SD 2.4) for concerns about public attitudes, and 6.7 (SD 2.5) for negative self-image.

Hornet platform In total, 1,824 participants completed the translated version of the Short HIV Stigma scale (98.4\% cisgender men and 1.6\% transgender/non-binary). Median age was 36 years (interquartile range 30-43), most were white (1121, 63\%), 495 (27\%) reported highincome, and 1233 (67\%) reported college education or higher (more than 12 years of education). Sexual orientation was reported as gay/homosexual by 1665 (91\%) and bisexual by 146 (8\%). Subscale scores were 5.5 (SD 2.5) for personalized stigma, 10.6 (SD 2.1) for disclosure concerns, 9.3 (SD 2.2) for concerns about public attitudes, and 7.3 (SD 2.6) for negative self-image.

Comparing the samples that include exclusively GBM, Grindr and Hornet (Table 2), we note important similarities in age, gender and sexual orientation. There were small differences in income and education (greater representation of lower income and less educated in the Hornet sample), and larger differences in the spatial distribution of participants: $93 \%$ of those using Hornet are from the South/Southeast. Comparing the two samples of GBM with social media participants, we note that participants from social media were older, reported lower education and income, and were more likely to have a partner $(50 \%$ social media vs $27 \%$ Grindr). Importantly, the social media sample allowed the inclusion of multiple genders: cisgender women (38\%), transgender/non-binary $(7 \%)$ and cisgender men (54\%), and of individuals of heterosexual orientation.

\section{Analysis 1: Grindr and social media samples Confirmatory factor analysis}

A four-factor structure showed good fit in both samples [Grindr: chi-square $(48)=56.9, p=0.17, \mathrm{CFI}=0.995$, $\mathrm{TLI}=0.993, \quad \mathrm{RMSEA}=0.040, \quad \mathrm{SRMR}=0.062 ;$ social media: chi-square $(48)=63.4, p=0.07, \mathrm{CFI}=0.993$, $\mathrm{TLI}=0.990, \quad \mathrm{RMSEA}=0.044, \quad \mathrm{SRMR}=0.047, \quad$ Additional file 1: Tables S1 and S2]. Construct validity was supported with overall high standardized loadings of items on the intended scales, except for items 10 (0.634) and $12(0.592)$ in the Grindr sample and items $8(0.555)$ and $10(0.436)$ in the social media sample. No modifications were made based on modification indices. 
Table 2 Characteristics of the three study samples

\begin{tabular}{|c|c|c|c|}
\hline & Grindr & Social media & Hornet \\
\hline Total & 114 & 164 & 1824 \\
\hline \multicolumn{4}{|l|}{ Age } \\
\hline Mean (SD) & $38.6(10.1)$ & $43.7(12.3)$ & $37.8(9.9)$ \\
\hline \multicolumn{4}{|l|}{ Age categories } \\
\hline $18-24$ & $8(7.0)$ & $6(3.7)$ & $103(5.6)$ \\
\hline $25-29$ & $16(14.0)$ & $21(12.8)$ & $301(16.5)$ \\
\hline $30-39$ & $39(34.2)$ & $38(23.2)$ & $721(39.5)$ \\
\hline $40-49$ & $33(28.9)$ & $42(25.6)$ & $423(23.2)$ \\
\hline $50-59$ & $16(14.0)$ & $38(23.2)$ & $238(13.0)$ \\
\hline $60+$ & $2(1.8)$ & 19 (11.6) & $38(2.1)$ \\
\hline \multicolumn{4}{|l|}{ Gender } \\
\hline Cisgender men & $114(100)$ & $89(54.3)$ & $1794(98.4)$ \\
\hline Cisgender women & $0(0)$ & $63(38.4)$ & $0(0)$ \\
\hline Transgender/non-binary & $0(0)$ & $12(7.3)$ & $30(1.6)$ \\
\hline \multicolumn{4}{|l|}{ Sexual orientation } \\
\hline Gay/homosexual & $104(91.2)$ & $87(54.0)$ & $1665(91.4)$ \\
\hline Bisexual & $10(8.8)$ & $6(3.7)$ & $146(8.0)$ \\
\hline Heterosexual & $0(0)$ & $68(42.2)$ & $9(0.5)$ \\
\hline \multicolumn{4}{|l|}{ Skin color/race } \\
\hline White & $63(56.8)$ & $75(46.3)$ & $1121(63.0)$ \\
\hline Black & $14(12.6)$ & $25(15.4)$ & $191(10.7)$ \\
\hline Pardo (Mixed)/native & $34(30.6)$ & $62(38.3)$ & $467(26.3)$ \\
\hline \multicolumn{4}{|l|}{ Income ${ }^{a}$} \\
\hline Low & $26(22.8)$ & $93(56.7)$ & $497(27.2)$ \\
\hline Middle & $57(50.0)$ & $58(35.4)$ & $832(45.6)$ \\
\hline High & $31(27.2)$ & $13(7.9)$ & $495(27.1)$ \\
\hline \multicolumn{4}{|l|}{ Education (years) ${ }^{b}$} \\
\hline$\leq 12$ & $30(26.5)$ & $100(61.0)$ & $565(31.4)$ \\
\hline$>12$ & $83(73.5)$ & $64(39.0)$ & $1233(68.6)$ \\
\hline \multicolumn{4}{|l|}{ Region ${ }^{c}$} \\
\hline Other & $36(31.6)$ & $27(16.5)$ & $121(6.6)$ \\
\hline Southeast/South & $78(68.4)$ & $137(83.5)$ & $1703(93.4)$ \\
\hline \multicolumn{4}{|l|}{ Partner } \\
\hline No & $83(72.8)$ & $82(50.0)$ & - \\
\hline Yes & $31(27.2)$ & $82(50.0)$ & - \\
\hline \multicolumn{4}{|c|}{ Short HIV Stigma Scale scores } \\
\hline \multicolumn{4}{|l|}{ Personalized stigma } \\
\hline Mean (SD) & $5.9(2.9)$ & $5.9(2.8)$ & $5.5(2.5)$ \\
\hline \multicolumn{4}{|l|}{ Disclosure concerns } \\
\hline Mean (SD) & $11.1(1.5)$ & $8.9(3.2)$ & $10.6(2.1)$ \\
\hline \multicolumn{4}{|c|}{ Concerns about public attitudes } \\
\hline Mean (SD) & $9.8(1.9)$ & $8.7(2.4)$ & $9.3(2.2)$ \\
\hline \multicolumn{4}{|l|}{ Negative self-image } \\
\hline Mean (SD) & $7.8(2.6)$ & $6.7(2.5)$ & $7.3(2.6)$ \\
\hline
\end{tabular}

a We considered the number of minimum wages in the family monthly income: low $\leq 2$, middle $>2-6$, high $>6$ (monthly minimum wage in 2019 was 998 $\mathrm{BRL}=$ US $\$ 248$, currency from January 2020)

b $\leq 12$ years is equivalent to complete Secondary Education or less, $>12$ is equivalent to complete College education or higher

c Other $=$ North, Northeast and Central-west regions

- Data not available

\section{Differential item functioning}

The four-factor model was fit to the combined samples (Grindr and social media), including a direct effect of group on the latent factors. Results indicate a good fit [chi-square $(56)=72.6, p=0.07, \mathrm{CFI}=0.995, \mathrm{TLI}=0.993$, RMSEA $=0.033$, SRMR $=0.038$ ]. Prior to accounting for possible DIF, Grindr participants had 0.02 SD lower personalized stigma factor levels than social media participants $(p=0.87)$. For the three other factors, Grindr participants had significantly higher factor levels: $0.97 \mathrm{SD}$ higher for disclosure concerns, 0.49 SD higher for concerns about public attitudes, and $0.25 \mathrm{SD}$ higher in negative self-image than social media participants $(p<0.01$ for all, Table 3). DIF analyses indicated that only item 10 ("I feel guilty that I have HIV") was significant, being endorsed at higher levels by Grindr participants (0.30 SD higher than social media participants, $p=0.02$ ).

As shown in Table 3, after correcting for DIF for item 10 , compared with the base model, there was a decrease of $0.06 \mathrm{SD}$ on the latent negative self-image factor for Grindr participants compared to social media, a negligible difference with no differences on the other factors. Thus, although there was statistically significant DIF on item 10, this did not substantively influence the overall estimates of HIV stigma latent factor scores between the two samples. After correcting for DIF, Grindr participants scored 0.97, 0.49 and 0.19 SD higher on the latent factors disclosure concerns, concerns about public attitudes, and negative self-image, respectively, than social media participants.

\section{Analysis 2: Hornet and social media samples Confirmatory factor analysis}

A four-factor structure showed good fit in the Hornet sample [chi-square $(54)=498.2, p<0.01, \mathrm{CFI}=0.980$, $\mathrm{TLI}=0.973$, RMSEA $=0.071, \mathrm{SRMR}=0.039$, Additional file 1: Table S3]. Construct validity was supported with overall high standardized loadings of all items (ranging from 0.671 for item 12 to 0.958 for item 5 ).

\section{Differential item functioning}

The four-factor model was fit to the combined samples (Hornet and social media), including a direct effect of group on the latent factors. Results indicate a good fit [chi-square $(56)=483.6, p<0.01, \mathrm{CFI}=0.983$, $\mathrm{TLI}=0.976$, RMSEA $=0.06, \mathrm{SRMR}=0.034]$. Prior to accounting for possible DIF, Hornet participants had 0.14 SD lower personalized stigma factor levels than social media participants $(p=0.05)$. For the three other factors, Grindr participants had significantly higher factor levels: $0.65 \mathrm{SD}$ higher for disclosure concerns, 0.24 SD higher for concerns about public attitudes, and 
Table 3 Factor loadings for the Short HIV Stigma scale in the base and DIF corrected models and influence of group on the overall estimates of latent factor scores: analysis 1 includes Grindr and social media samples and analysis 2 includes Hornet and social media samples

\begin{tabular}{|c|c|c|c|c|}
\hline \multirow[t]{2}{*}{ Short HIV stigma items } & \multicolumn{2}{|c|}{$\begin{array}{l}\text { Analysis 1: Grindr and social media } \\
\text { samples }\end{array}$} & \multicolumn{2}{|c|}{$\begin{array}{l}\text { Analysis } 2 \text { : Hornet and social } \\
\text { media samples }\end{array}$} \\
\hline & Base model & DIF corrected & Base model & DIF corrected \\
\hline \multicolumn{5}{|l|}{ Personalized stigma } \\
\hline People I care about stopped calling after learning I have HIV & 0.896 & 0.896 & 0.854 & 0.854 \\
\hline I have lost friends by telling them I have HIV & 0.883 & 0.883 & 0.901 & 0.901 \\
\hline Some people avoid touching me once they know I have HIV & 0.853 & 0.853 & 0.860 & 0.860 \\
\hline \multicolumn{5}{|l|}{ Disclosure concerns } \\
\hline I work hard to keep my HIV a secret & 0.945 & 0.945 & 0.900 & 0.900 \\
\hline Telling someone I have HIV is risky & 0.946 & 0.946 & 0.955 & 0.955 \\
\hline I am very careful who I tell that I have HIV & 0.908 & 0.908 & 0.861 & 0.861 \\
\hline \multicolumn{5}{|l|}{ Concerns about public attitudes } \\
\hline Most people believe a person who has HIV is dirty & 0.839 & 0.839 & 0.839 & 0.839 \\
\hline People with HIV are treated like outcasts & 0.614 & 0.614 & 0.732 & 0.732 \\
\hline Most people are uncomfortable around someone with HIV & 0.745 & 0.745 & 0.813 & 0.813 \\
\hline \multicolumn{5}{|l|}{ Negative self-image } \\
\hline I feel guilty because I have HIV & 0.529 & 0.503 & 0.677 & 0.673 \\
\hline People's attitudes about HIV make me feel worse about myself & 0.891 & 0.895 & 0.872 & 0.872 \\
\hline I feel I'm not as good a person as others because I have HIV & 0.662 & 0.660 & 0.670 & 0.670 \\
\hline \multicolumn{5}{|l|}{ Structural effect of group on latent factor ${ }^{\mathrm{a}}$} \\
\hline Personalized stigma & -0.020 & -0.020 & -0.145 & -0.145 \\
\hline Disclosure concerns & 0.969 & 0.969 & 0.647 & 0.647 \\
\hline Concerns about public attitudes & 0.487 & 0.487 & 0.243 & 0.243 \\
\hline Negative self-image & 0.252 & 0.194 & 0.180 & 0.120 \\
\hline \multicolumn{5}{|l|}{ Direct effect on item attributable to group } \\
\hline I feel guilty because I have HIV (item 10) & & 0.298 & & 0.219 \\
\hline
\end{tabular}

a Social Media group is reference

Italics indicate $p$ value $<0.01$

0.18 SD higher in negative self-image than social media participants $(p<0.01$ for all, Table 3). DIF analyses indicated that only item 10 ("I feel guilty that I have HIV") was significant, being endorsed at higher levels by Hornet participants $(0.22 \mathrm{SD}$ higher than social media participants, $p<0.01$ ).

After correcting for DIF for item 10, compared with the base model, there was a decrease of $0.06 \mathrm{SD}$ on the latent negative self-image factor for Hornet participants compared to social media, a negligible difference with no differences on the other factors. Thus, although there was statistically significant DIF on item 10, this did not substantively influence the overall estimates of HIV stigma latent factor scores between the two samples. After correcting for DIF, Hornet participants scored 0.65 , and $0.24 \mathrm{SD}$ higher on the latent factors disclosure concerns and concerns about public attitudes, respectively, than social media participants.

\section{Reliability}

Considering all samples combined, reliability as measured by Cronbach's alpha, ordinal alpha and omega were, respectively, $0.85,0.91$ and 0.91 for personalized stigma; $0.87,0.93$, and 0.94 for disclosure concerns; $0.76,0.84$, and 0.84 for concerns about public attitudes; 0.69, 0.78, 0.78 for negative self-image; and $0.83,0.88$ and 0.93 for the entire scale.

\section{Construct validity}

Results showed that participants reached by the Grindr platform who were not on antiretroviral treatment scored higher than those on treatment, no differences were observed for the social media sample and, for Hornet participants, those on antiretroviral treatment scored higher than those not on treatment (Table 4). A more consistent correlation was found between antiretroviral treatment adherence and subscale scores. Among the 


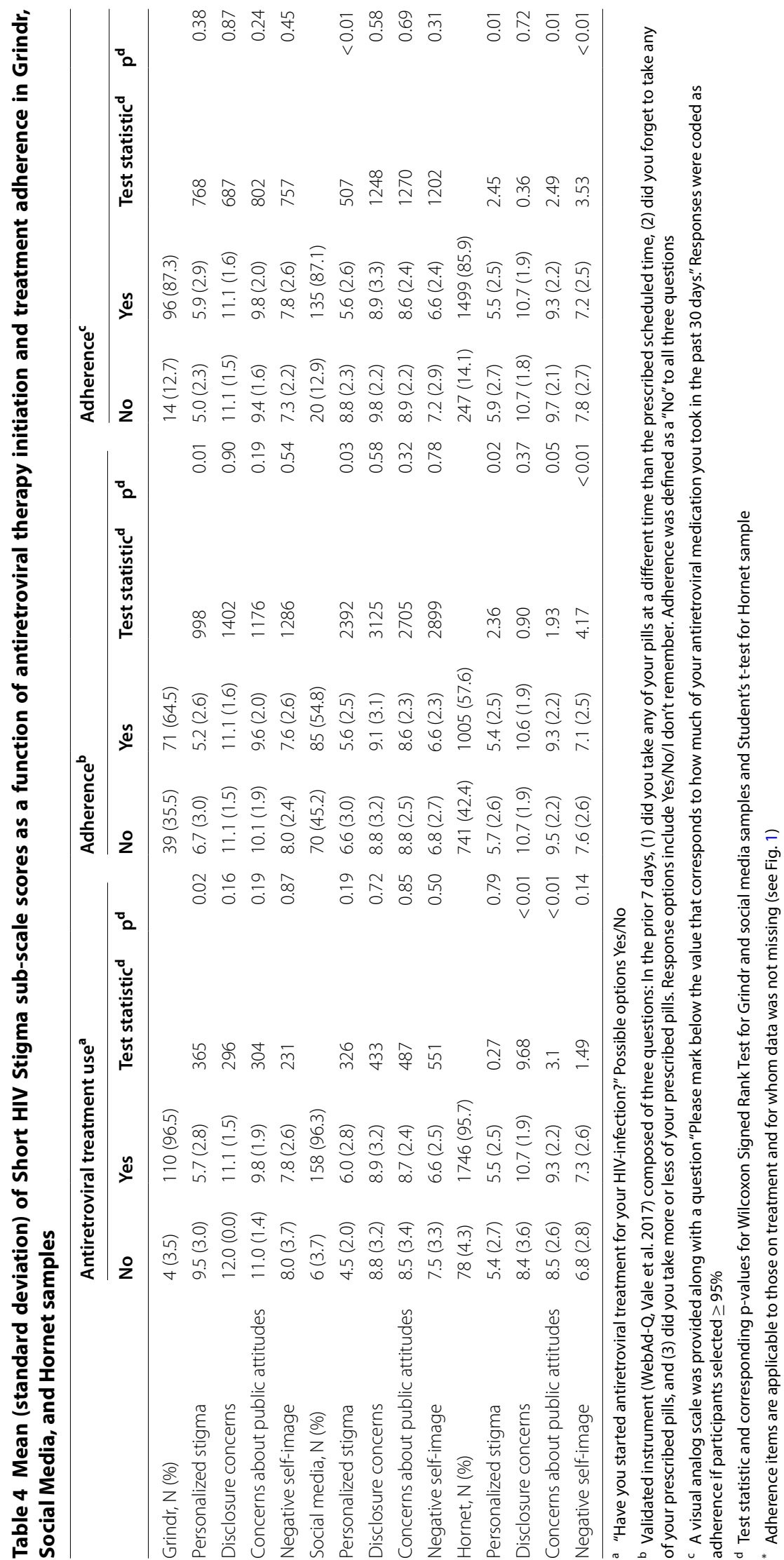


three samples and the two adherence measures, participants who self-reported non-adherent on the Web-Ad$\mathrm{Q}$ and the visual analog scale scored higher than those who were adherent on personalized stigma. Additionally, among participants from Hornet, those who were nonadherent scored higher with respect to concerns about public attitudes and negative self-image.

\section{Discussion}

In this study, we employed multiple steps and techniques to translate and validate the Short HIV Stigma scale in Brazilian Portuguese. Our results represent a first assessment of the Short HIV Stigma scale in this population and future studies are needed to expand our results. Nonetheless, we found that the Brazilian Portuguese version of the Short HIV Stigma scale had satisfactory psychometric properties and construct validity was supported by the correlations between subscale scores and the use of and adherence to antiretroviral treatment. Of particular importance is the possible occurrence of differential item functioning that "can be conceptualized as a form of measurement bias, where individuals respond to items on a scale as a function of some attribute other than what the scale is designed to measure" [50]. We found significant differential item functioning of negligible magnitude $(\mathrm{SD}=0.06)$ for one item addressing feelings of guilt ("I feel guilty because I have HIV"). As such, our findings suggest that the Short HIV Stigma scale may be used in different populations in Brazil and that score comparisons can be made without concern that measurement differences may substantively influence results.

Although our results did not evidence DIF of relevant magnitude between groups, we did observe large differences in the levels of the construct. Grindr and Hornet participants scored significantly higher on the latent factors disclosure concerns and concerns about public attitudes, and $\sim 0.20 \mathrm{SD}$ higher on the latent factor negative self-image, than social media participants. In the absence of DIF, these would appear to be actual differences in the three of the four dimensions of the construct being measured (HIV-related stigma). HIV-infected GBM are prone to other forms of stigma including homonegativity, or the negative attitudes a person has towards his own homosexuality [51]. In a study of older (aged 50-65 years) HIV-infected GBM, authors reported how HIV stigma coupled with two other forms of stigma (homonegativity and ageism) explained $39 \%$ of the variance associated with selfreported quality of life [51]. The stereotype of HIV as a disease of gay men coupled with Brazil's heterosexist and anti-gay society could lead to a higher HIV-related stigma among GBM. Moreover, as suggested [52], these societal-level conditions and cultural-norms may act synergistically and more severely affect the physical and mental health of GBM.

There are several study limitations to highlight. Our three samples were recruited from different web-based platforms, and there was a difference in sample size between the samples. As such, the core model from analysis 1 used to assess DIF relied more on data from social media participants than those from Grindr, while for analysis 2, it relied more on data from Hornet participants than those from social media. Since the initial confirmatory factor analysis yielded similar model structures for all samples, it does not seem likely that the different sample sizes influenced results substantially. Due to the cross-sectional design of the study, test-retest reliability and sensitivity to change of the translated Short HIV Stigma scale could not be assessed. Also, participants were recruited from convenience samples and not through a random sampling of people living with HIV. It is possible that our participants vary systematically from the entire population of people living with HIV, and this may have impacted our findings and decreased the generalizability of our results. Compared to people living with HIV in Brazil [1], our sample was older, had less women, and was mostly from the Southeast/South.

\section{Conclusions}

Studies are needed for a more accurate and realistic understanding of how HIV-related stigma hinders Brazil's response to the HIV epidemic. A validated instrument to measure HIV-related stigma should empower studies to evaluate its impact on the well-being of populations. We hope that the availability of a validated Short HIV Stigma scale will foster studies in Brazil using a standardized instrument, thus allowing for better comparison across studies. Indeed, we believe that this short instrument will be particularly useful in a scenario where multiple additional constructs could be measured and their interplay explored.

\section{Supplementary information}

Supplementary information accompanies this paper at https://doi. org/10.1186/s12955-020-01571-1.

Additional file 1. Supporting information for manuscript by Luz et al. Translation and validation of the Short HIV Stigma Scale in Brazilian Portuguese.

\section{Acknowledgements}

We would like to thank Roberto Gonçalves Ramalho for the valuable contribution and guidance during instrument translation. We are grateful for support from the Coordination for the Improvement of Higher Education Personnel (CAPES). 


\section{Funding}

Dr. Luz was supported by Programa Inova FIOCRUZ, Edital Geração do Conhecimento/VPPCB, and Programa PrInt, Coordenação de Aperfeiçoamento de Pessoal de Nível Superior (CAPES)/FIOCRUZ. Dr. Torres was supported by Conselho Nacional de Desenvolvimento Científico e Tecnológico (CNPq, \#28/2018). Dr. Thombs was supported by a Fonds de recherche du Québec Santé Distinguished Scholar Award.

\section{Availability of supporting data}

The datasets used and/or analyzed during the current study are available from the corresponding author on reasonable request.

\section{Ethics approval}

This study was approved by INI Evandro Chagas-FIOCRUZ institutional review board (\#CAAE 01777918.0.0000.5262) in accordance with all applicable regulations.

\section{Consent for publication}

All authors fulfill the criteria for authorship, and have read and approved the final version of this manuscript.

\section{Competing interests}

The authors declare that they have no competing interests.

\section{Author details}

${ }^{1}$ Instituto Nacional de Infectologia Evandro Chagas, Fundação Oswaldo Cruz, Av. Brasil 4365, Manguinhos, Rio de Janeiro 21040-900, Brazil. ${ }^{2}$ Research Institute of the McGill University Health Centre, Montreal, Canada. ${ }^{3}$ Department of Applied Statistics, Social Science, and Humanities, New York University, New York, NY, USA. ${ }^{4}$ Center for Practice and Research and the Intersection of Information, Society, and Methodology, New York University, New York, NY, USA.

${ }^{5}$ Lady Davis Institute for Medical Research, Jewish General Hospital, Montréal, Québec, Canada. ${ }^{6}$ Departments of Psychiatry; Epidemiology, Biostatistics and Occupational Health; Medicine; Psychology; Educational and Counselling Psychology, and Biomedical Ethics Unit, McGill University, Montréal, Québec, Canada.

Received: 6 June 2020 Accepted: 21 September 2020 Published online: 02 October 2020

\section{References}

1. MS. Boletim epidemiologico de DST e AIDS. Departamento de DST/AIDS e Hepatites Virais. Secretaria de Vigilancia em Saude. Ministerio da Saude, Brasilia. 2019. www.aids.gov.br. Accessed 19 Apr 2020.

2. Benzaken AS, Oliveira MCP, Pereira GFM, Giozza SP, Souza FMA, Cunha $A$, et al. Presenting national HIV/AIDS and sexually transmitted disease research in Brazil. Medicine (Baltimore). 2018;97(1S Suppl 1):S1-S2.

3. Sousa Al, Pinto VLJ. Spatial and temporal analysis of aids cases in Brazil, 1996-2011: increased risk areas over time. Epidemiol Serv Saude. 2016;25(3):467-76.

4. Pascom ARP, Meireles MV, Benzaken AS. Sociodemographic determinants of attrition in the HIV continuum of care in Brazil, in 2016. Medicine (Baltimore). 2018;97(1S Suppl 1):S69-S74.

5. Massignam FM, Bastos JL, Nedel FB. Discrimination and health: a problem of access. Epidemiol Serviços Saúde. 2015;24(3):541-4.

6. Fitzgerald-Husek A, Van Wert MJ, Ewing WF, Grosso AL, Holland CE, Katterl R, et al. Measuring stigma affecting sex workers (SW) and men who have sex with men (MSM): a systematic review. PLoS ONE. 2017;12(11):e0188393.

7. Sabidó M, Kerr LR, Mota RS, Benzaken AS, Pinho AD, Guimaraes MD, et al. Sexual violence against men who have sex with men in Brazil: a respondent-driven sampling survey. AIDS Behav. 2015;19(9):1630-41.

8. Kerr LR, Mota RS, Kendall C, Pinho Ade A, Mello MB, Guimaraes MD, et al. HIV among MSM in a large middle-income country. AIDS. 2013;27(3):427-35.

9. MacCarthy S, Brignol S, Reddy M, Nunn A, Dourado I. Making the invisible, visible: a cross-sectional study of late presentation to HIV/AIDS services among men who have sex with men from a large urban center of Brazil. BMC Public Health. 2014;14:1313.

10. Macinko J, Mullachery P, Proietti FA, Lima-Costa MF. Who experiences discrimination in Brazil? Evidence from a large metropolitan region. Int J Equity Health. 2012;11:80.

11. Andersson GZ, Reinius M, Eriksson LE, Svedhem V, Esfahani FM, Deuba K, et al. Stigma reduction interventions in people living with HIV to improve health-related quality of life. Lancet HIV. 2020;7(2):e129-e140140.

12. Reinius M, Wettergren $L$, Wiklander M, Svedhem V, Ekstrom AM, Eriksson LE. Development of a 12-item short version of the HIV stigma scale. Health Qual Life Outcomes. 2017;15(1):115.

13. Rueda S, Mitra S, Chen S, Gogolishvili D, Globerman J, Chambers L, et al. Examining the associations between HIV-related stigma and health outcomes in people living with HIV/AIDS: a series of meta-analyses. BMJ Open. 2016;6(7):e011453.

14. Gesesew HA, Tesfay Gebremedhin A, Demissie TD, Kerie MW, Sudhakar M, Mwanri L. Significant association between perceived HIV related stigma and late presentation for HIV/AIDS care in low and middleincome countries: a systematic review and meta-analysis. PLOS ONE. 2017;12(3):e0173928.

15. Rendina HJ, Weaver L, Millar BM, Lopez-Matos J, Parsons JT. Psychosocial well-being and HIV-related immune health outcomes among HIV-positive older adults: support for a biopsychosocial model of HIV stigma and health. J Int Assoc Provid AIDS Care. 2019;18:2325958219888462.

16. de Almeida MR, Labronici LM. The silent itinerary of people with HIV told through oral history. Cien Saude Colet. 2007;12(1):263-74.

17. Kerrigan D, Vazzano A, Bertoni N, Malta M, Bastos Fl. Stigma, discrimination and HIV outcomes among people living with HIV in Rio de Janeiro, Brazil: the intersection of multiple social inequalities. Glob Public Health. 2017;12(2):185-99.

18. Ojikutu BO, Pathak S, Srithanaviboonchai K, Limbada M, Friedman R, Li S, et al. Community cultural norms, stigma and disclosure to sexual partners among women living with HIV in Thailand, Brazil and Zambia (HPTN 063). PLoS ONE. 2016;11(5):e0153600

19. Pinho AA, Barbosa RM, Brignol S, Villela W, Monteiro SS. Drivers of sexual inactivity among women living with HIV and AIDS: findings of the GENIH Study in Sao Paulo. Brazil Arch Sex Behav. 2018;47(7):1983-93.

20. Índice de estigma em relação às pessoas vivendo com HIV/AIDS, Brasil. 2020.https://www.stigmaindexorg/wp-content/uploads/2020/03/Brazi I-SI-Report-2019 Portuguese.pdf. Accessed 10 Aug 2020

21. Earnshaw VA, Chaudoir SR. From conceptualizing to measuring HIV stigma: a review of HIV stigma mechanism measures. AIDS Behav. 2009;13(6):1160-77.

22. Emlet CA. A comparison of HIV stigma and disclosure patterns between older and younger adults living with HIV/AIDS. AIDS Patient Care STDS. 2006;20(5):350-8.

23. Fife BL, Wright ER. The dimensionality of stigma: a comparison of its impact on the self of persons with HIV/AIDS and cancer. J Health Soc Behav. 2000:41(1):50-67.

24. Holzemer WL, Uys LR, Chirwa ML, Greeff M, Makoae LN, Kohi TW, et al. Validation of the HIV/AIDS stigma instrument-PLWA (HASI-P). AIDS Care. 2007;19(8):1002-12.

25. Kalichman SC, Simbayi LC, Cloete A, Mthembu PP, Mkhonta RN, Ginindza T. Measuring AIDS stigmas in people living with HIV/AIDS: the Internalized AIDS-Related Stigma Scale. AIDS Care. 2009;21(1):87-93.

26. Sayles JN, Hays RD, Sarkisian CA, Mahajan AP, Spritzer KL, Cunningham WE. Development and psychometric assessment of a multidimensional measure of internalized HIV stigma in a sample of HIV-positive adults. AIDS Behav. 2008;12(5):748-58.

27. Van Rie A, Sengupta S, Pungrassami P, Balthip Q, Choonuan S, Kasetjaroen $Y$, et al. Measuring stigma associated with tuberculosis and HIV/AIDS in southern Thailand: exploratory and confirmatory factor analyses of two new scales. Trop Med Int Health. 2008;13(1):21-30.

28. Berger BE, Ferrans CE, Lashley FR. Measuring stigma in people with HIV: psychometric assessment of the HIV stigma scale. Res Nurs Health. 2001;24(6):518-29.

29. Lindberg MH, Wettergren L, Wiklander M, Svedhem-Johansson V, Eriksson LE. Psychometric evaluation of the HIV stigma scale in a Swedish context. PLOS ONE. 2014;9(12):e114867.

30. Franke MF, Munoz M, Finnegan K, Zeladita J, Sebastian JL, Bayona JN, et al. Validation and abbreviation of an HIV stigma scale in an 
adult spanish-speaking population in urban Peru. AIDS Behav. 2010;14(1):189-99.

31. Jeyaseelan L, Kumar S, Mohanraj R, Rebekah G, Rao D, Manhart LE. Assessing HIV/AIDS stigma in south India: validation and abridgement of the Berger HIV Stigma scale. AIDS Behav. 2013;17(1):434-43.

32. Yu CH, Huang CY, Lee YT, Cheng SF. Development of an 18-item abbreviated Chinese version of Berger's HIV Stigma Scale. Int J Nurs Pract. 2019;25(2):e12708.

33. Beaton DE, Bombardier C, Guillemin F, Ferraz MB. Guidelines for the process of cross-cultural adaptation of self-report measures. Spine (Phila Pa 1976). 2000;25(24):3186-91.

34. Vale FC, Santa-Helena ET, Santos MA, Carvalho W, Menezes PR, Basso CR, et al. Development and validation of the WebAd-Q Questionnaire to monitor adherence to HIV therapy. Rev Saude Publica. 2018;52:62.

35. Costa JM, Torres TS, Coelho LE, Luz PM. Adherence to antiretroviral therapy for HIV/AIDS in Latin America and the Caribbean: systematic review and meta-analysis. J Int AIDS Soc. 2018;21(1):e25066.

36. Muthén LK, Muthén BO. Mplus User's Guide. Eigth ed. Los Angeles: Muthén \& Muthén; 2017.

37. McDonald RP, Ho MH. Principles and practice in reporting structural equation analyses. Psychol Methods. 2002;7(1):64-82.

38. Tucker $L R$, Lewis $C$. A reliability coefficient for maximum likelihood factor analysis. Psychometrika. 1973;38:1-10.

39. Bentler PM. Comparative fit indexes in structural models. Psychol Bull. 1990;107(2):238-46.

40. Steiger JH. Structural model evaluation and modification: an interval estimation approach. Multivariate Behav Res. 1990;25(2):173-80.

41. Jackson DL, Gillaspy JA, Purc-Stephenson R. Reporting practices in confirmatory factor analysis: an overview and some recommendations. Psychol Methods. 2009;14(1):6-23.

42. Reise SP, Widaman KF, Pugh RH. Confirmatory factor analysis and item response theory: two approaches for exploring measurement invariance. Psychol Bull. 1993;114(3):552-66.

43. Hu L, Bentler PM. Cutoff criteria for fit indexes in covariance structure analysis: conventional criteria versus new alternatives. Struct Equ Model. 1999:6:1-55.
44. Delisle VC Kwakkenbos L, Hudson M Baron M. Thombs BD, Canadian Scleroderma Research $G$. An assessment of the measurement equivalence of English and French versions of the Center for Epidemiologic Studies Depression (CES-D) Scale in systemic sclerosis. PLoS ONE. 2014:977):e102897.

45. Kwakkenbos $L$, Arthurs $E$, van den Hoogen FH, Hudson M, van Lankveld WG, Baron $\mathrm{M}$, et al. Cross-language measurement equivalence of the Center for Epidemiologic Studies Depression (CES-D) scale in systemic sclerosis: a comparison of Canadian and Dutch patients. PLoS ONE. 2013;8(1):e53923

46. Kwakkenbos L, Minton O, Stone PC, Alexander S, Baron M, Hudson M, et al. Can the cancer-related fatigue case-definition criteria be applied to chronic medical illness? A comparison between breast cancer and systemic sclerosis. J Rheumatol. 2015;42(7):1156-62.

47. Taber KS. The use of Cronbach's alpha when developing and reporting research instruments in science education. Res Sci Educ. 2018:48:1273-96.

48. Gadermann AM, Guhn M, Zumbo BD. Estimating ordinal reliability for Likert-type and ordinal item response data: a conceptual, empirical, and practical guide. Pract Assess Res Eval. 2012;17(3):13

49. R Core Team. R: A language and environment for statistical computing. $R$ Foundation for Statistical Computing, Vienna, Austria. 2019.

50. Lewis TT, Yang FM, Jacobs EA, Fitchett G. Racial/ethnic differences in responses to the everyday discrimination scale: a differential item functioning analysis. Am J Epidemiol. 2012;175(5):391-401.

51. Slater LZ, Moneyham L, Vance DE, Raper JL, Mugavero MJ, Childs G. The multiple stigma experience and quality of life in older gay men with HIV. J Assoc Nurses AIDS Care. 2015;26(1):24-35.

52. Hatzenbuehler ML. Structural stigma: research evidence and implications for psychological science. Am Psychol. 2016;71(8):742-51.

\section{Publisher's Note}

Springer Nature remains neutral with regard to jurisdictional claims in published maps and institutional affiliations.
Ready to submit your research? Choose BMC and benefit from:

- fast, convenient online submission

- thorough peer review by experienced researchers in your field

- rapid publication on acceptance

- support for research data, including large and complex data types

- gold Open Access which fosters wider collaboration and increased citations

- maximum visibility for your research: over $100 \mathrm{M}$ website views per year

At BMC, research is always in progress.

Learn more biomedcentral.com/submissions 